\title{
TrafFic Signals GENERATION WITH BICOLOR LEDS USING PIC 18F SERIES MICROCONTROLLER
}

\author{
Karthick Kumar Reddy, G. Jagadeesh, P. and Venkatramana Reddy, S.* \\ Department of Physics, Sri Venkateswara University, Tirupati-517502, Andhra Pradesh, \\ India. \\ *drsvreddy123@gmail.com
}

\begin{abstract}
PIC $18 F$ series microcontroller is used for control of signals to a specific time using port lines. In this contest we choose the Bicolor LEDs with Red and Green. The colors of the signals are illuminated by programming in the microcontroller. The aim of this paper is to generate three colors on a single traffic light instead of using three different color traffic signal lights. The purpose of this design is to reduce the manufacture cost of the signal lights and to use a minimum number of ports in a microcontroller and cable lines to transmit the signals to the light source. This paper describes a new design for the traffic signals.
\end{abstract}

\section{KEYWORDS}

PIC 18F8720 Microcontroller, Bicolor LEDs, Signal generation, 74LS273 Latch, MPLAB IDE Software.

\section{INTRODUCTION}

Traffic lights are signalling devices positioned at road intersections, pedestrian crossings and other locations to control competing flows of traffic. They assign the right of way to road users by the use of lights in standard colors (red - amber/yellow - green), using a universal color code. Design of an effective traffic light system in a modern city is a task of traffic engineers, and is an important undertaking. Traffic lights need to be placed judiciously to result in the safest and fastest movement of people and vehicles. In this contest the most important is the timing of traffic signals. In the centers to save energy, lamps are replaced in traffic lights with light emitting diodes (LEDs), which use very little energy. An additional advantage of LEDs is longer service life, save a lot of energy and has less impact on the environment [1]. Instead of using different color LEDs for different colors, we are using single bicolor led (SSL-LX5097IGW). To illuminate traffic signals at a regular interval of time, the lights were interfaced to microcontrollers. A microcontroller contains a simple microprocessor core along with all necessary data and program memory. For this purpose it adds all peripherals that allow it to do interfacing. These may include digital and analog input and output or counting elements. Like any electronic circuits the microcontroller needs to be powered, and needs a clock signal to drive the internal logic circuits [2]. Among all the different type of microcontrollers available in the market, the number of products using 8-bit microcontrollers has experienced explosive growth in 
the last decade, and the number of applications is growing [3]. The focus of this paper is to generate traffic signals using PIC $18 \mathrm{~F}$ series 8-bit microcontroller. In microcontroller based systems, the latch is used as an Input/Output Interfacing device, and a system designer can assign a binary address to the latch, called Input/output port address. A latch (74LS273) is a storage device that can store one bit. When the latch is enabled, it can receive information from the processor, latch it and display it at output peripherals [4].

In bicolour Red/Green LED we have two anodes A1, A2 and one cathode K. The bicolor LED SSL-LX5097IGW is shown in Figure 1.

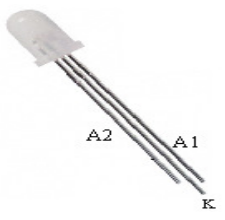

Figure 1. Bicolor LED (Model: SSL-LX5097IGW)

If anode A1 is High and cathode is connected to ground then Red color is emitted, if A2 is High then green color is emitted. If two anodes are connected to High then both colors are emitted so they appear as Yellow/Amber. A natural phenomenon is when Red and Green colors are combined produces Yellow color. Based on this logic the three different colors of the Traffic Signals are generated by choosing a single bicolor Red/Green LED. Also the wave length for Green color at $2.1 \mathrm{~V}$ is $565 \mathrm{~nm}$ and for Red color at $2.1 \mathrm{~V}$ is $635 \mathrm{~nm}$ [5]. So, the mean wavelength for two colors is $600 \mathrm{~nm}$ and approximate to Yellow color wavelength.

\section{EXPERIMENTAL DETAILS}

\subsection{Hardware for the System}

A microcontroller is an electronic device that includes three components: Microprocessor, Memory and I/O on a single semiconductor unit called an Integrated Circuit. In addition to these components, the microcontroller includes many supporting devices as shown in Figure 2. In this paper, we use PIC 18F8720 and is available in 80 pin TQFP package and the features are summarized in Table $1[6]$.

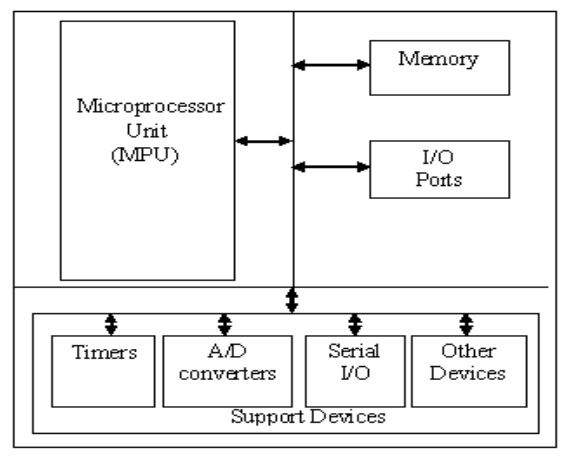

Figure 2. Block diagram of Microcontroller with support devices 
The Universal Embedded Trainer supplied by Vi Microcontroller, Chennai, India is for 8, 16, 32 bit microcontroller development system and can be used either as a standalone system or as a system with serial interface to personal computer. We can communicate this trainer to Personal Computer Via serial port. The boot loader program is programmed in microcontroller, so we can access easily [7].

Table 1. PIC18F8720 design features

\begin{tabular}{|l|l|c|}
\hline Device & PIC 18F8720 \\
\hline \multirow{2}{*}{ Program Memory } & Bytes & $128 \mathrm{~K}$ \\
\cline { 2 - 3 } & $\begin{array}{l}\text { \# Single-Word } \\
\text { Instructions }\end{array}$ & 65536 \\
\hline \multirow{2}{*}{ Data Memory } & SRAM (bytes) & 3840 \\
\cline { 2 - 3 } EEPROM (bytes) & 1024 \\
\hline I/O & 68 \\
\hline 10-bit A/D(ch) & 16 \\
\hline CCP (PWM) & SPI & 5 \\
\hline \multirow{2}{*}{ MSSP } & Master I2C & Yes \\
\hline USART & Yes \\
\hline Timers 8-bit/16-bit & $2 / 3$ \\
\hline Ext Bus & Yes \\
\hline Max FOSC (MHz) & 25 \\
\hline
\end{tabular}

PORT D is a "bidirectional" port in PIC18F8720 and it should be set up by writing instructions as an output port that can transfer binary bits to LEDs. Therefore, logic1 is required to turn on LEDs [2]. The interfacing of Bicolor LEDs to Microcontroller via Latch is shown in figure 3. In the

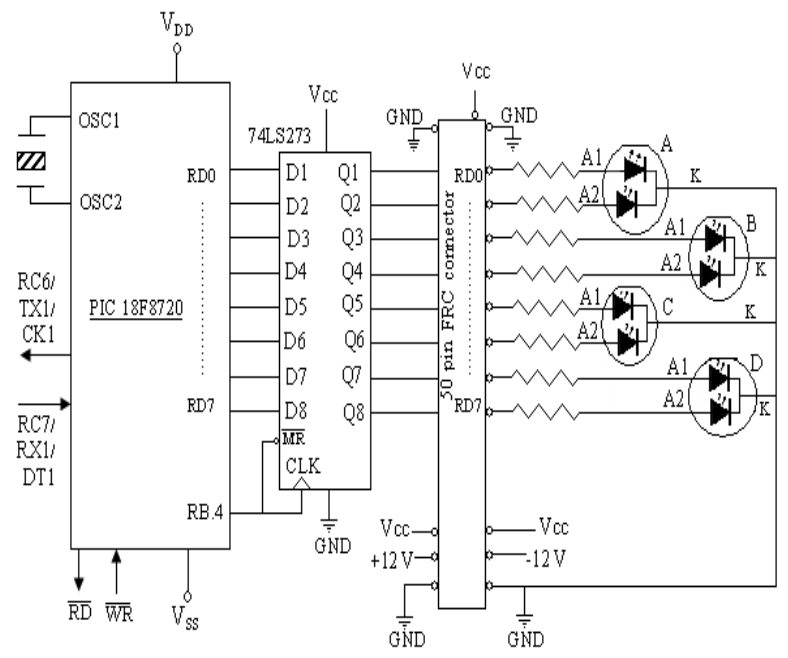

Figure 3. Interfacing Bicolor LEDs to PIC 18F8720 Via Latch for Generation of Traffic Signals in four roads Junction

parallel data transfer mode, a complete Byte is transferred simultaneously over the entire data bus. The data transfer from I/O Ports to traffic signals is in the parallel mode. Eight Anodes of 4 Bicolor LEDs are connected to eight I/O pins- RD0 to RD7 of Port D lines through 74LS273 latch. Latch CLK pin is enabled via PORT B.4. Digital data are sent to Port D lines. According to the digital data, bicolor LEDs glow. The connections from Ports of Microcontroller to latch and to bicolor LEDs are shown in Figure 3. 


\subsection{Software for the System}

The software Program was developed in $\mathrm{C}$ language for initializing the Ports, and the Program is written in MPLAB IDE software. MicroProcessor LABoratory is an Integrated Development Environment that can be downloaded free from Microchip website [8]. It contain all the software tools necessary to write a program in Assembler, Assemble it, Simulate it, and then download it to a programmer. Screen image from MPLAB version 8.66 is shown in Figure 4.

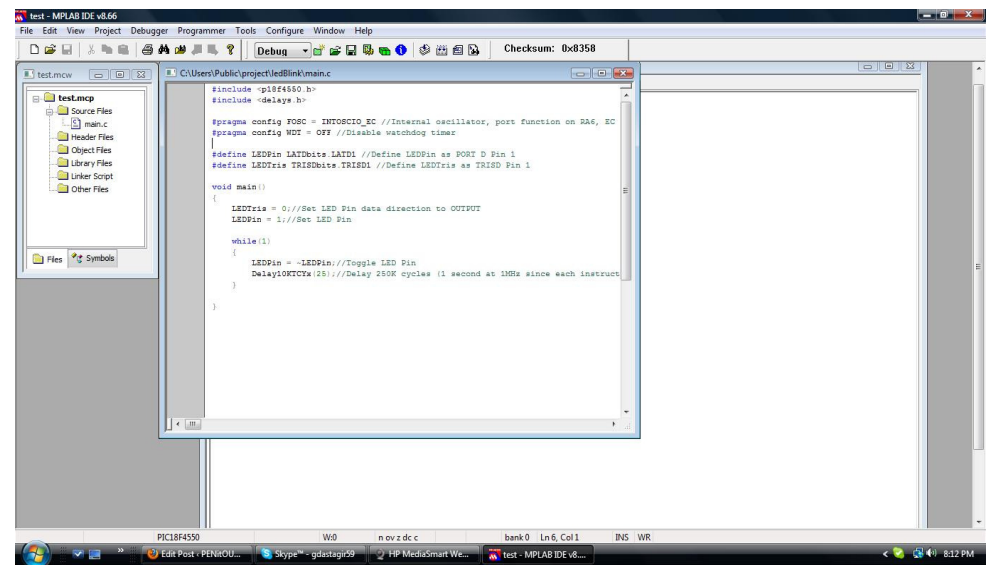

Figure 4. Screen image of MPLAB IDE version 8.66

MPLAB IDE runs on a Personal Computer and contains all the components needed to design and deploy embedded systems applications. Figure 4 shows MPLAB IDE window. The device should be choose as PIC 18F8720 in the configure menu. From project menu Language Tool suite should be CCS C compiler for PIC12/14/16/18. A new project file is opened, saved then program to Traffic Signals for 4 Junction roads is written and compiled. If the output window is shown "BUILD SUCCEDDED" then the program is executed on trainer. To execute the program in a microcontroller transfer hex file via serial communication port from personal computer. This transfer of hex file is done by PIC ISP 18Fxxxx serial downloader. Tiny switch is provided in the trainer for programming and execution. During transfer of hex file, switch should be in prog.mode and click download button in PIC ISP 18Fxxxx window. After download is complete the switch position is change to exec.mode and reset the CPU. Code will be executed [7, 9]. The block diagram of PC connected to trainer via RS 232 cable is shown in Figure 5. The bicolor LEDs A, B, C, D are towards R1, R2, R3, R4 roads respectively shown in Figure 5.

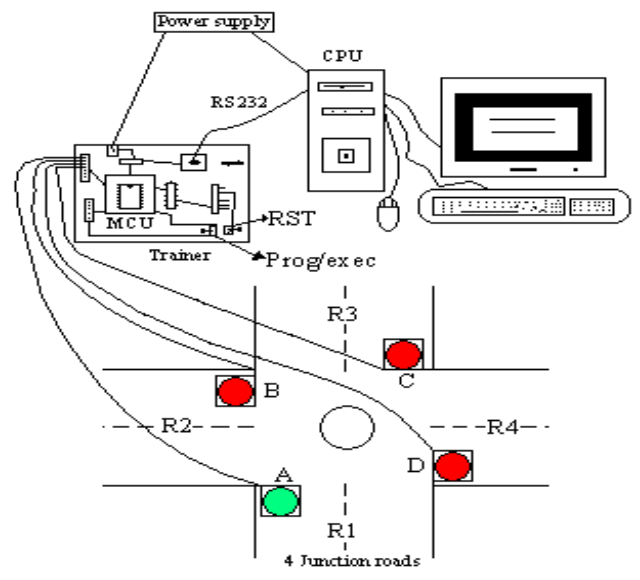

Figure 5. Block diagram of PC connected to trainer via RS 232 cable and generated Traffic Signal 
International Journal of Embedded Systems and Applications (IJESA) Vol.1, No.2, December 2011

\subsubsection{Flow chart}

The execution of the program in terms of step by step process is explained by the use of flow chart shown in Figure 6.

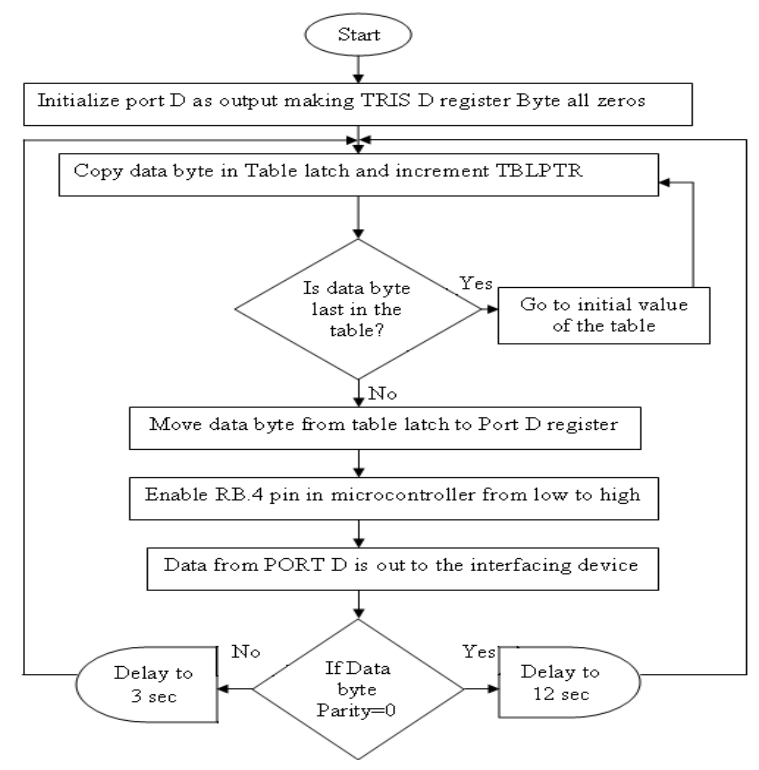

Figure 6. Flow chart for Traffic signals generation with PIC 18F8720 Microcontroller

In the program, the value from Table latch are fetched and moved to port $\mathrm{D}$ register to make port $\mathrm{D}$ as output. For this choosing TRIS D register byte all zeros and increment TBLPTR [3]. Table-2 shows the data byte (Hex values) to be initialize to port $\mathrm{D}$ register. The data on port $\mathrm{D}$ register is out to interfacing device, when port B.4 pin is enabled 74LS273 latch CLK pin from Low-toHigh. The Green color light is emitted by the bicolor LED A to R1 road and Red to remaining roads, and the next data byte is transferred only after delay. The LEDs glow according to the data transferred to port D register. Thus the traffic is controlled in 4 roads Junction by generating Traffic Signals through PIC18F8720 microcontroller.

Table 2. Initialize Hex values to Port D register

\begin{tabular}{|c|c|c|c|c|c|c|c|c|c|c|}
\hline \multirow{2}{*}{$\begin{array}{l}\text { LEDS } \\
\text { Colors }\end{array}$} & \multicolumn{2}{|c|}{$A$} & \multicolumn{2}{|c|}{$\mathrm{B}$} & \multicolumn{2}{|c|}{6} & \multicolumn{2}{|c|}{$\mathrm{D}$} & \multirow{2}{*}{$\begin{array}{l}\mathrm{Hex} \\
\text { valtues }\end{array}$} & \multirow{2}{*}{$\begin{array}{l}\text { TELPTR } \\
\text { addres } s\end{array}$} \\
\hline & $\mathrm{R}$ & $\mathrm{O}$ & $\mathrm{R}$ & 0 & $\mathrm{R}$ & 9 & $\mathrm{R}$ & 9 & & \\
\hline & 0 & 1 & 1 & 0 & 1 & 0 & 1 & 0 & GA & $\times \times \times 0$ \\
\hline & 1 & 1 & 1 & 0 & 1 & 0 & 1 & 0 & EA & $\times \propto 1$ \\
\hline & 1 & 0 & 0 & 1 & 1 & 0 & 1 & 0 & 9 व & $\times \propto 2$ \\
\hline & 1 & 0 & 1 & 1 & 1 & 0 & r & 0 & $\mathrm{BA}$ & $\times \times \times 3$ \\
\hline & 1 & 0 & 1 & 0 & 0 & 1 & 1 & 0 & $\Delta 6$ & $\times \times<4$ \\
\hline & 1 & 0 & 1 & 0 & 1 & 1 & 1 & 0 & $\mathrm{AE}$ & $\times \times 5$ \\
\hline & 1 & 0 & 1 & 0 & 1 & 0 & 0 & 1 & $\Delta 9$ & KК⿴ \\
\hline & 1 & 0 & 1 & 0 & 1 & 0 & 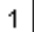 & 1 & A日 & $\times \propto \times 7$ \\
\hline Prort D & & & & & & & & & & \\
\hline
\end{tabular}

\section{Conclusions}

Traffic signals for 4 roads Junction are activated by using the PIC $18 \mathrm{~F}$ series microcontroller. In the traffic signals we made an adjustment that instead of using three different color LED signals 
lights, we assembled with a bicolor Red/Green LED signal light which emits three colors (RedGreen-Yellow). Through this design the cost of manufacturing the signal lights is reduced to low because number of LEDs used for signals are less, a minimum number of I/O port lines are used in Microcontroller. We need three port lines for three color signals control for a single road way but by the use of bicolor LEDs only two port lines are sufficient. So, if I/O port lines in microcontroller are used minimum number, then rest may be used for other applications.

\section{ACKNOWLEDGEMENTS}

The authors are thankful to University Grants Commission (UGC), New Delhi for providing the necessary financial assistance under UGC-CAS program.

\section{REFERENCES}

[1] Traffic light - Wikipedia, the free encyclopedia. Available: http://en.wikipedia.org/wiki/Traffic_light

[2] Ramesh S. Gaonkar (2010) Fundamentals of Microcontrollers and Applications in Embedded systems (with the PIC 18 microcontrollers Family), Penram International Publishers (India) Pvt. Ltd.

[3] Muhammad Ali Mazidi, Rolind D. Mckinlay, Danny Causey (2009) PIC Microcontrollers and Embedded Systems Using Assembly and C for PIC 18, 1st ed., Pearson Education.

[4] 74LS273 Datasheet pdf - Octal D-type Positive-edge-triggered Flip... Available: http://www.datasheetcatalog.com/datasheets_pdf/7/4/L/.../74LS273.shtml

[5] Led 5mm red/green diff bicolor. Available: http://parts.digikey.com/1/parts/681935-led-5mm-redgreen-diff-bicolor-ssl-1x5097igw.html

[6] Microchip PIC18F6520/8520/6620/8620/6720/8720 Data Sheet. Available: http:// ww1.microchip.com/downloads/en/devicedoc/39609b.pdf

[7] Universal Embedded Trainer Technical Reference Version-1.2, M/S Vi Microsystems Pvt. Ltd.

[8] Microchip Technology Website. Available: http:// www.microchip.com.

[9] Tim Wilmshurst (2010) Designing embedded systems with PIC Microcontrollers: Principles and Applications, 2nd ed, Elsevier Publishers.

\section{Authors}

Dr. S.Venkatramana Reddy received M.Phil. and Ph.D. degrees in Physics in 1996, 2001 respectively from Sri Venkateswara University, Tirupati, Andhra Pradesh, India. He taught the subjects Semiconductor Devices \& Circuits, Analog and Digital Electronics, 8051 Microcontrollers \& Applications, Embedded Systems using PIC microcontrollers, Advanced Microprocessors \& Microcomputers, Electronic Instrumentation, Industrial Control Electronics, Analog \& Digital Communication, Microwave and Satellite communication, Optical Fiber Communications, Advanced Communication Systems, etc. to the students of M.Sc. Electronics/ M.Tech. Energy Management/ M.Sc. Physics since from the academic year 1995-1996. He has been actively involved in designing M.Sc. Electronics

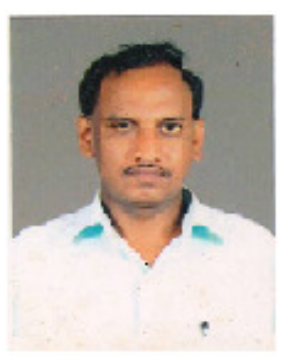
Course in the University. He has published more than 24 research papers in internationally reputed Journals and presented several papers at National Conferences/Symposia. He attended Six Electronics oriented Training Courses/Workshops/National Schools. He is Fellow, Institution of Electronics and Telecommunication Engineers, New Delhi and Life member (LM) in many Professional Bodies like the Instrument Society of India, Bangalore, Semiconductor Society (India), New Delhi, Indian Physics Association, BARC, Mumbai, Indian Association of Physics Teachers, Kanpur, Uttar Pradesh. At present he is working as An Assistant Professor in the Department of Physics, S.V. University, Tiruipati. 
International Journal of Embedded Systems and Applications (IJESA) Vol.1, No.2, December 2011

Mr. G. Karthick Kumar Reddy obtained his M.Sc. in Physics with Electronics as specialization from Sri Venkateswara University in the year 2009. He is presently doing Ph.D in the Department of Physics, Sri Venkateswara University.

Mr. P. Jagadeesh obtained his M.Sc. degree in Physics from the Andhra University in the Year 2002. He is doing M.Phil degree in the Department of Physics, Sri Venkateswara University.
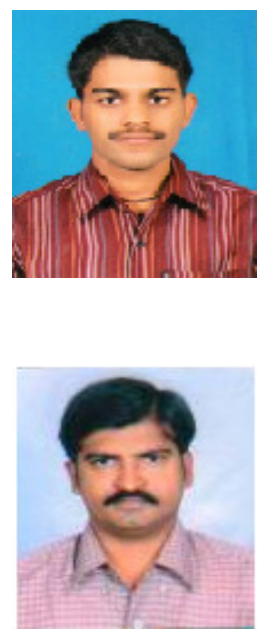